\title{
GROUND-BASED TESTING OF REPLACEMENT THERMAL CONTROL MATERIALS FOR THE HUBBLE SPACE TELESCOPE
}

Jacqueline A. Townsend, Patricia A. Hansen, Mark W. McClendon, NASA Goddard Space Flight Center, Greenbelt, Maryland, 20771 USA

Kim K. de Groh, Bruce A. Banks

NASA Lewis Research Center, Cleveland, Ohio 44135 USA

Jack. J. Triolo

Swales Aerospace, Beltsville, Maryland 20705 USA 


\begin{abstract}
The mechanical and optical properties of the metallized Teflon ${ }^{12}$ FEP thermal control materials on the Hubble Space Telescope (HST) have degraded over the nearly seven years the telescope has been in orbit. Given the damage to the outer layer of the multi-layer insulation (MLI) that was apparent during the second servicing mission (SM2), the decision was made to replace the outer layer during subsequent servicing missions. A Failure Review Board was established to investigate the damage to the MLI and identify a replacement material. The replacement material had to meet the stringent thermal requirements of the spacecraft and maintain mechanical integrity for at least ten years.

Ten candidate materials were selected and exposed to ten-year HST-equivalent doses of simulated orbital environments. Samples of the candidates were exposed sequentially to low and high energy electrons and protons, atomic oxygen, $\mathrm{x}$-ray radiation, ultraviolet radiation and thermal cycling. Following the exposures, the mechanical integrity and optical properties of the candidates were investigated using Optical Microscopy, Scanning Electron Microscopy (SEM), a Laboratory Portable Spectroreflectometer (LPSR) and a Lambda 9 Spectroreflectometer. Based on the results of these simulations and analyses, the Failure Review Board selected a replacement material and two alternates that showed the highest likelihood of providing the requisite thermal properties and surviving for ten years in orbit.
\end{abstract}




\section{INTRODUCTION}

The Hubble Space Telescope (HST) was launched into low Earth orbit (LEO) in April 1990 with Multi-Layer Insulation (MLI) blankets on the Light Shield, Forward Shell, and several Equipment Bays [1]. The outer layer of these multi-layer blankets was aluminized Teflon ${ }^{\circledR}$ FEP (fluorinated ethylene propylene). Following the First Servicing Mission (SM1) in December 1993, analysis of retrieved MLI blankets revealed that the outer layer was beginning to degrade [1]. When astronauts rendezvoused with the telescope during the Second Servicing Mission (SM2) in February 1997, they discovered severe cracking in the outer layer of the MLI blankets on both solar facing and anti-solar facing surfaces of HST. A small specimen of the outer layer was retrieved for ground-based analysis $[1,2]$.

Testing of the MLI specimen that was returned during SM2 revealed that the cracks observed on HST were a form of slow crack growth, which meant that they occurred slowly, under low stress, in the presence of a degrading environmental factor $[2,4]$. The Teflon ${ }^{\circledast}$ FEP had completely lost plastic deformation capability, indicating that significant chain scission had occurred [3]. The material also showed increased density and crystallinity [3, 5]. The solar absorptance of the Teflon ${ }^{\circledR}$ FEP had increased due to bulk changes in the Teflon ${ }^{\circledR}$ FEP and cracking in the vapor deposited aluminum (VDA) backing $[3,6,7,8]$. This damage appeared to be the result of the combination of bulk damage from radiation exposure (electrons and protons) and the nearly 40,000 thermal cycles $\left(-100\right.$ to $\left.+50^{\circ} \mathrm{C}\right)$ the MLI experienced.

Given the severity of the damage, HST management decided it was likely that repairs to the outer layer would be required during the next servicing mission (SM3) in May, 2000. A Failure Review Board (FRB) was tasked to recommend a replacement material to be deployed during SM3 on the Light Shield that would last through the spacecraft end-of-life (EOL) in 2010. The recommended material was required to maintain structural integrity over the course of ten years and have an EOL solar absorptance over hemispherical emittance ratio $(\alpha / \varepsilon)$ of less than 0.28 . 
In order to find a replacement material, the FRB selected ten promising candidate materials and subjected them to simulations of the HST orbital environment. The exposure and testing effort involved facilities at Boeing Space Systems and three NASA centers: Marshall Space Flight Center (MSFC), Lewis Research Center (LeRC), and Goddard Space Flight Center (GSFC). Following the exposures, the specimens were evaluated in terms of crack propagation, crack morphology and optical properties.

\section{MATERIALS}

\subsection{Candidate Selection Process}

The FRB brainstormed a list of seventeen materials that could possibly meet the needs of the project. Due to time and funding constraints, it was not possible to test all seventeen of these materials. To determine which materials would be pursued, the board established a list of performance criteria and rated the brainstormed materials. These nine criteria are listed below:

1. Low solar absorptance/thermal emittance ratio $\alpha / \varepsilon<0.28$ at EOL

2. Ability to maintain structural integrity

3. Compatibility with EVA installation

4. Tear resistance

5. Not a source of contamination

6. Commercial availability for SM3 mission

7. Has demonstrated record of long term in-space durability in LEO

8. Suitable to construct a functional outer layer

9. Stowability

The FRB members rated the predicted performance of a material in each of the criteria. In doing so, the damage to the current Teflon ${ }^{\star}$ FEP material was considered along with the issues specific to each of the brainstormed materials. Scores from each board member for each performance criterion were used in a multiplicative evaluation formula to calculate an overall score for each material. Based on this process, the original list of seventeen brainstormed materials was pared down to six candidate replacement materials. Four materials were added to the list at the discretion of the FRB chair for reasons outlined in Section 2.2. These ten materials were exposed 
to simulated space environments, and their performances were evaluated with respect to the performance criteria in order to make the final selection.

\subsection{Candidates}

Ten candidate replacement materials were evaluated in simulated low Earth orbit environments. Through this work the numbers below are used to refer to each material.

1. 10 mil Teflon FEP/VDS/Inconel/non-UV-darkening adhesive/Nomex ${ }^{\otimes}$ scrim

2. 5 mil Teflon ${ }^{\star}$ FEP/VDS/Inconel/adhesive/fiberglass scrim/adhesive/2 mil Kapton ${ }^{\star}$

3. 10 mil Teflon ${ }^{\otimes}$ FEP/VDA/non-UV-darkening adhesive/Nomex ${ }^{*}$ scrim

4. 5 mil Teflon ${ }^{\star}$ FEP/VDA/non-darkening adhesive/fiberglass scrim/adhesive/2 mil Kapton ${ }^{\star}$

5. 5 mil Teflon FEP/VDS/Inconel/non-UV-darkening adhesive/Nomex ${ }^{\otimes}$ scrim

6. 5 mil Teflon FEP /VDA/non-UV-darkening adhesive/Nomex scrim

7. OCLI multi-layer oxide UV blocker $/ 2$ mil white Tedlar ${ }^{\infty}$

8. 5 mil Teflon ${ }^{\otimes}$ FEP/VDA (the current material)

9. $\mathrm{SiO}_{2} / \mathrm{Al}_{2} \mathrm{O}_{3} / \mathrm{Ag} / \mathrm{Al}_{2} \mathrm{O}_{3} / 4$ mil stainless steel

0 . Proprietary Teflon ${ }^{\infty}$ FEP/AZ93 White Paint/Kapton ${ }^{\infty}$

The first six materials were chosen based on the selection process described in section 2.1 .

Given the stringent thermal requirements (EOL $\alpha / \varepsilon<0.28$ ), the options for candidate replacement

materials were limited. Metallized Teflon ${ }^{\circledR}$ FEP met those thermal requirements, and photos taken

during SM2 revealed that bonded Teflon ${ }^{\circledR}$ FEP used on HST had maintained its structural integrity.

Because of this, several versions of Teflon ${ }^{\circledR}$ FEP/VDA and /VDS (vapor deposited silver) bonded to a scrim were candidates.

The last four materials were included in the testing for other reasons. The current material (material 8) was included to verify that the test procedure could produce damage similar to that observed in orbit. Material 7 was included because it was used on HST exterior surfaces in other applications, and HST management wanted to anticipate its performance. Materials 9 and 10 were included at the discretion of the FRB Chair. Since the materials chosen through the selection process were so similar, materials 9 and 10 were included so that fundamentally different materials were evaluated in the event that none of the first six was successful. 


\section{EXPERIMENTAL}

Since there was no facility for simultaneous exposure to a LEO-equivalent environment, the specimens were exposed to several environmental factors sequentially. The order of the exposures was designed to cause the maximum damage. Based on the penetration depth, it was thought that the electron and proton exposures were most likely to damage the bulk of the material. Therefore, the particle radiation exposures were completed first, so that the bulk of the material was compromised during subsequent exposures. Based on attenuation length, $\mathrm{x}$-rays from solar flares could also damage the bulk of the material. So, simulated solar flare $\mathrm{x}$-ray exposure (10 keV molybdenum, non-monochromated) occurred following charged particle exposure. Atomic oxygen was expected to damage only the surface of the material. Since the damaged surface could serve as crack initiation points, these exposures were done next. Thermal cycling was expected to cause a type of fatigue damage to embrittled material and to cause the mudtile effect in the metal backing. It seemed that the worst damage would occur if thermal cycling was completed after the material was embrittled. So, thermal cycling was performed following the exposure to electrons, protons and simulated flare $\mathrm{x}$-rays or AO. Ultraviolet radiation was expected to pass through the bulk material and interact with any adhesive that had bled through the mudtiled metal layer. It was therefore the final exposure in the sequence.

Since the cracks in the HST materials were a form of slow crack growth, it was necessary to provide both the environmental factor and low stress in each simulation. In orbit, the stress was most likely associated with the thermal cycling [3]. Since the specimens could not be thermal cycled during exposures to other environmental factors, special holders were developed to maintain the specimens at constant strain while they were exposed to electrons, protons and $\mathrm{AO}$.

Four sets of the candidates were exposed to electrons and protons at one of two facilities: MSFC or Boeing Space Systems Radiation facility. Following the electron/proton exposure, two sets were exposed to AO, and then thermal cycled at GSFC. Two other sets were exposed to $x$ rays at LeRC and thermal cycled at either LeRC or GSFC. The fluence values for these exposures were based on estimates of the HST environment. 


\subsection{Specimen Preparation}

Samples of the candidates were procured from several different vendors. Specimens with VDA were purchased from Dunmore and were backed with their proprietary, non-UV-darkening, polyester adhesive. Specimens with VDS were purchased from Sheldahl and were backed with their proprietary, non-UV-darkening, polyester adhesive. Material 7 was obtained from GSFC stock; material 8 was supplied by Lockheed Martin Missiles and Space from current stock; and material 9 was manufactured in the Thermal Engineering Branch at GSFC. Material 0 was provided by its manufacturer, AZTek. Specimen preparation was done in the Materials Engineering Branch and the Thermal Engineering Branch at GSFC.

The full sheet of each candidate was cured according to the manufacturer's specifications. Some were vacuum baked for up to 24 hours; others were received fully cured. Then each sheet was cleansed with an extracted clean-room wipe soaked in analytical-grade isopropyl alcohol. The sheets were then wrapped around a $0.5 \mathrm{~cm}$ diameter dowel along two axes to pre-stress the metal backing. Specimens were then cut in five different sizes to accommodate the test fixtures at each exposure facility (see Table 1). A microtome blade was used to cut the individual specimens with identical orientation from a single sheet of each candidate material. A new blade was used for each material. Control specimens were cut at the same time and stored in a lab at GSFC. Witness specimens were also cut and traveled with the test specimens to each test site.

\section{TABLE 1: SPECIMEN DIMENSIONS}

\begin{tabular}{|c|c|c|}
\hline $\begin{array}{c}\text { Specimen } \\
\text { Set }\end{array}$ & Materials & $\begin{array}{c}\text { Dimensions } \\
\text { (length } \times \text { width, cm) }\end{array}$ \\
\hline M1 & 6 Candidates & $12.7 \times 1.27$ \\
M2 & $\begin{array}{c}\text { 6 Candidates } \\
\text { M3 }\end{array}$ & $12.7 \times 5.08$ \\
& mil Teflon ${ }^{\infty}$ FEP/VDA & $12.7 \times 1.27$ \\
B1, B2 & 6 Candidates +4 Extras & $12.7 \times 3.81$ \\
B3 & 5 mil Teflon FEP/VDA & $12.7 \times 3.81$ \\
G1 & 6 Candidates + 4 Extras & $5.08 \times 5.08$ \\
L1 & 6 Candidates + 4 Extras & varied: $15.24 \times 12.7$ to \\
& & $25.4 \times 20.32$ \\
\hline
\end{tabular}


In order to provide a region of stress concentration, each specimen in sets M1, M2, M3, $\mathrm{B} 1, \mathrm{~B} 2$ and B3 was sliced through one quarter of its width at a point $5.08 \mathrm{~cm}$ from its top. The slices were cut from the inside to the edge of the specimen using a microtome blade. The load used during the radiation exposures was calculated to provide $1000 \mathrm{psi}$ in the net section of a $127 \mu \mathrm{m}$ thick specimen.

Once the specimens were cut they were photographed, and then the test and witness specimens were vacuum baked at $50{ }^{\circ} \mathrm{C}$ until the outgassing rate had dropped below the requirements for HST $\left(1.56 \times 10^{-9} \mathrm{~g} / \mathrm{cm}^{2} / \mathrm{hr}\right)$. Following bakeout, the solar absorptance was measured, and the specimens were hand-carried to the first exposure site.

\subsection{Environmental Exposures}

Sets of the candidates were exposed to several factors of the space environment so that the combined effects of the environment could be assessed. In addition to the combined exposures, the effects of thermal cycling and ultraviolet radiation (UV) were evaluated individually. The exposures and set designations are summarized in Table 2. Sample sets were named according to the facility that performed the first exposure. Sets that began with " $M$ " were first exposed at MSFC; "B" sets went to Boeing; "L" sets went to LeRC; and "G" sets remained at GSFC.

TABLE 2: CANDIDATE EXPOSURE SUMMARY

\begin{tabular}{|c|c|c|c|c|c|c|c|c|c|c|}
\hline \multirow{2}{*}{$\begin{array}{c}\text { Exposure } \\
\text { Set }\end{array}$} & \multirow{2}{*}{$\begin{array}{c}\text { First } \\
\text { Exposure } \\
\text { Location }\end{array}$} & \multicolumn{3}{|c|}{ Electron Exposures } & \multirow{2}{*}{$\begin{array}{c}\text { Proton } \\
\text { Energy } \\
\text { (keV) }\end{array}$} & \multirow[b]{2}{*}{$\begin{array}{c}\mathrm{AO} \\
\text { (years) }\end{array}$} & \multirow[b]{2}{*}{$\begin{array}{l}X \text {-ray } \\
\text { (years) }\end{array}$} & \multicolumn{2}{|c|}{ Thermal Cycles } & \multirow[b]{2}{*}{$\begin{array}{c}\text { UV } \\
\text { (ESH) }\end{array}$} \\
\hline & & $\begin{array}{c}\text { Duration } \\
\text { (years) }\end{array}$ & Type & $\begin{array}{c}\text { Energy } \\
(\mathrm{keV})\end{array}$ & & & & $\#$ & Load & \\
\hline M1 & MSFC & 10 & Dose & 50 to 500 & 700 & 10 & - & 20,000 & taped & - \\
\hline M2 & MSFC & 10 & Dose & 50 to 500 & 700 & - & 10 & 3,200 & taped & 505 \\
\hline M3 & MSFC & 6.8 & Dose & 50 to 500 & 700 & 6.8 & - & 20,000 & taped & - \\
\hline $\mathrm{B} 1$ & Boeing & 10 & Fluence & 40 & 40 & - & 10 & 1,000 & spring & - \\
\hline $\mathrm{B} 2$ & Boeing & 10 & Fluence & 40 & 40 & - & - & - & - & - \\
\hline B3 & Boeing & 6.8 & Fluence & 40 & 40 & - & - & - & - & - \\
\hline $\mathrm{Ll}$ & LeRC & - & - & - & - & - & - & $>1500$ & mass & - \\
\hline Gl & GSFC & - & - & - & - & - & - & - & - & 374 \\
\hline
\end{tabular}




\subsubsection{Combined Environmental Exposures}

Six sets of specimens (M1, M2, M3, B1, B2, B3) were exposed sequentially to aspects of the space environment at several different facilities.

\subsubsection{MSFC Exposure Facilities}

Three environmental factors were simulated at MSFC: electrons, protons and AO. During each of these exposures, the specimens were mounted to induce the 1000 psi stress described in section 3.1 .

The electron and proton exposures were completed using their Combined Environmental Effects (CEE) test system. The MSFC staff calculated the dose versus depth profile for HST fluences for each candidate. They then designed a fluence of $50 \mathrm{keV}, 220 \mathrm{keV}$ and $500 \mathrm{keV}$ electrons and $700 \mathrm{keV}$ protons which matched that profile as closely as possible. During the CEE exposure, the specimens were under vacuum $\left(5 \times 10^{-7}\right.$ Torr $)$ and were subjected to the electrons of various energies simultaneously and then protons. For all specimens, the exposure times were less than one hour. Specimen sets M1 and M2 were exposed to ten-year HST doses of electrons and protons. Set M3 (the current HST material) was exposed to an SM2-equivalent dose to determine if the observed damage to HST could be duplicated with the test plan [8].

Following electron and proton exposures, two sets (M1 and M3) were exposed to $\mathrm{AO}$ in their Atomic Oxygen Beam Facility (AOBF). The fluences of the exposures were monitored with control specimens of Kapton ${ }^{\star} \mathrm{H}$ and pristine Teflon ${ }^{\star}$ FEP. The flux was estimated based on measurements of the AO ion current neutralized by the system during a standard run. Set M1 was exposed to a ten-year equivalent HST fluence. Set M3 was exposed to an SM2-equivalent fluence [8].

\subsubsection{Boeing Exposure Facilities}

Three material sets were exposed to electron and proton fluences at Boeing Information, Space and Defense Systems, Radiation Effects Laboratory [8]. Rather than matching the dose versus depth profile, the Boeing facility matched the total HST fluence of electrons and protons with $40 \mathrm{keV}$ electrons and $40 \mathrm{keV}$ protons. During the exposure, the specimens were under load. 
Sets B1 and B2 were exposed to ten-year HST fluences. Set B3, the current HST material, was exposed to a SM2-equivalent fluence [8]. Following this exposure, no further testing was performed on sets B2 and B3 so that they would be available if any tests or simulations were needed in the future.

\subsubsection{LeRC Exposure Facilities}

Two types of exposures were completed at LeRC: $x$-ray exposures and thermal cycling. The samples were exposed to simulated solar flare $\mathrm{x}$-rays in a modified electron beam evaporator system. A water-cooled molybdenum (Mo) target was irradiated with a $10 \mathrm{keV}$ electron beam. The target was angled to allow the highest flux of $\mathrm{x}$-rays to irradiate the candidate materials. The electron beam current was run low enough to prevent any evaporation of the target material. A model AXUV-20HEI absolute XUV silicone photodiode, produced by International Radiation Detectors Inc., was used to measure the x-ray flux during each sample exposure run. The photodiode has 100 percent quantum efficiency over the range of photon energies produced by the source. Two sheets of $2 \mu \mathrm{m} \mathrm{Al}$ foil were used as a barrier between the target and the photodiode and samples during the exposures. The $\mathrm{Al}$ foil blocked energetic electrons from the target and blocked the detector from visible light from the electron beam emitter. A photographic cloth was used to block room light to the detector. Two sets (M2 and B1) were exposed to ten-year HSTequivalent fluences of non-monochromatic Mo x-rays. Set B1 was then thermal cycled at LeRC.

The LeRC thermal cycling device was comprised of two nitrogen-purged thermal chambers dwelling at the two temperature limits, -100 and $+50{ }^{\circ} \mathrm{C}$. Specimens were held vertically and raised or lowered from one chamber to the other with a mechanical arm. The cycle time, roughly 5 minutes, was driven by the temperature of an exposed thermocouple. The specimens were spring loaded so that they were stressed throughout the cycle (1800 psi) [7]. Set B1 received 1000 thermal cycles in this chamber.

\subsubsection{GSFC Exposure Facilities}

Rapid thermal cycling and UV exposures were carried out at GSFC. Rapid thermal cycling between $-100^{\circ} \mathrm{C}$ and $+60^{\circ} \mathrm{C}$ took place in a modified thermal cycle chamber with a nitrogen purge. 
Liquid nitrogen vapor and a heat gun were added to the chamber to reduce the period of the cycles to 15 to 20 seconds. Temperatures were monitored with thermocouples taped around the test specimen, and the cycle was driven by a thermocouple affixed with epoxy to a control specimen mounted adjacent to the test specimen [8]. Following electron, proton and AO exposures, sets $\mathrm{M} 1$ and M3 received 20,000 cycles at GSFC. Set M2 received 3,200 cycles following electron, proton and $\mathrm{x}$-ray exposures.

The GSFC UV exposures were done in vacuum using a Spectralab X-25 Solar Simulator equipped with a Xenon lamp. The radiation had a minimum wavelength of $180 \mathrm{~nm}$. Following thermal cycling set M2 was exposed to 374 equivalent sun hours (ESH).

\subsubsection{Individual Environmental Exposures}

In addition to the combined effects, the effects of thermal cycling on larger specimens and UV exposure were evaluated.

\subsubsection{Large Specimen Thermal Cycling}

Since most of the candidate materials were layered with scrim, concerns were raised about the possibility that thermal cycling could result in permanent deformation of the materials due to mismatched coefficients of thermal expansion or creep properties. Problems in this area could result in severe handling issues or failure of the material in orbit. The specimens used in the combined effects exposures were too small to address these concerns. Considerably larger specimens (set L1) were thermal cycled at LeRC in order to assess the degree of deformation [8].

Specimens were subjected to at least 1500 cycles with a roughly 9 minute period in the thermal chamber described in section 3.2.1.3. Before and after cycling, the specimens were evaluated for fractional distortion. Fractional distortion was defined as $d / h$, where $h$ was the height of the suspended specimen and $d$ was the maximum displacement from true vertical (see Figure 1). The values are reported in Table $3[8]$.

The LeRC investigators concluded that shape distortion was a major concern for materials 4 and 7 [8]. This conclusion was based on both the initial fractional distortion and the condition following thermal cycling. Although material 6 also had considerable distortion, because the 
specimen was wavy, rather than curled in a single direction, the distortion was not considered to be a major concern.

FIGURE 1: FRACTIONAL DISTORTION, d/h [8]

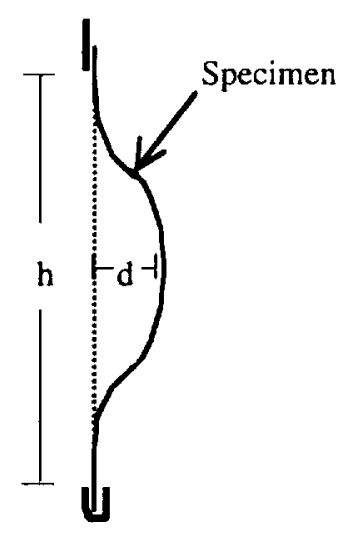

TABLE 3: FRACTIONAL DISTORTION (d/h) FROM THERMAL CYCLING [8]

\begin{tabular}{|c|c|c|c|c|}
\hline Material \# & Initial d/h & Final d/h & $\Delta$ & Comments \\
\hline 3 & 0.020 & 0.032 & 0.012 & \\
4 & 0.008 & 0.073 & 0.065 & Convex \\
6 & 0.020 & 0.063 & 0.043 & Wavy \\
7 & 0.046 & 0.049 & 0.003 & Concave \\
8 & 0.026 & 0.025 & 0.001 & \\
9 & 0.012 & 0.012 & 0.000 & \\
\hline
\end{tabular}

\subsubsection{Ultraviolet Radiation Exposures}

In order to prove the UV stability of the proprietary adhesives provided by the vendors, the G1 specimens were exposed to ultraviolet radiation and then tested for changes in solar absorptance. These measurements were made in air using a Laboratory Portable Spectroreflectometer (LPSR). The G1 set consisted of two specimens for each candidate material. The specimens were handled vigorously in order to break the metal backing in every specimen so that the UV could reach the adhesive. They were then exposed in the UV chamber (described in section 3.2.1.4) at the beginning of the test plan and remained there as long as possible before the final FRB meeting. Following the meeting, the selected candidate was placed back in the chamber. 
It was exposed until the rate of absorptance change had decreased to the point that any further change would not be significant. The solar absorptance at 1144 ESH was defined as the predicted maximum value. The pre- and post-exposure solar absorptance values are recorded in Table 4 .

TABLE 4: SOLAR ABSORPTANCE PRE- AND POST-UV EXPOSURE

\begin{tabular}{|c|c|c|c|c|}
\hline \multirow[b]{2}{*}{ Material } & \multirow{2}{*}{$\begin{array}{c}\text { Sample } \\
. \#\end{array}$} & \multicolumn{3}{|c|}{ Solar Absorptance After 374 ESH } \\
\hline & & Initial & Post-UV & $\Delta$ \\
\hline $10 \mathrm{mil}$ FEP/VDS/Inconel/adhesive/Nomex & 1 & $0.117,0.094$ & $0.107,0.094$ & $-0.010,0$ \\
\hline $\begin{array}{l}5 \mathrm{mil} \mathrm{FEP/VDS/Inconel/adhesive/} \mathrm{fiberglass} \\
\text { scrim/adhesive/Kapton }\end{array}$ & 2 & $0.082,0.081$ & $0.080,0.075$ & $-0.002,-0.006$ \\
\hline 10 mil FEP/VDA/adhesive Nomex & 3 & $0.164,0.164$ & $0.174,0.175$ & $0.010,0.011$ \\
\hline $\begin{array}{l}5 \text { mil FEP/VDA/adhesive/fiberglass } \\
\text { scrim/adhesive/Kapton }\end{array}$ & 4 & $0.186,0.187$ & $0.189,0.194$ & $0.003,0.007$ \\
\hline 5 mil FEP/VDS/Inconel/adhesive/Nomex & 5 & $0.095,0.086$ & $0.083,0.083$ & $-0.008,-0.003$ \\
\hline 5 mil FEP/VDA/adhesive/Nomex & 6 & $0.144,0.137$ & $0.142,0.143$ & $-0.002,0.006$ \\
\hline 5 mil FEP/VDA & 8 & $0.138,0.135$ & $0.153,0.143$ & $0.015,0.008$ \\
\hline $\mathrm{SiO}_{2} / \mathrm{Al}_{2} \mathrm{O}_{3} / \mathrm{Ag} / \mathrm{Al}_{2} \mathrm{O}_{3} / 4$ mil stainless steel & 9 & $0.074,0.079$ & $0.079,0.082$ & $0.005,0.003$ \\
\hline \multicolumn{5}{|c|}{ After $1144 \mathrm{ESH}$} \\
\hline 5 mil FEP/VDA/adhesive/Nomex & 6 & & $0.151,0.155$ & $0.007,0.180$ \\
\hline $\mathrm{SiO}_{2} / \mathrm{Al}_{2} \mathrm{O}_{3} / \mathrm{Ag} / \mathrm{Al}_{2} \mathrm{O}_{3} / 4$ mil stainless steel & 9 & & $0.094,0.088$ & $0.020,0.009$ \\
\hline
\end{tabular}

\section{RESULTS}

General observations and solar absorptance values in air were recorded before and after each exposure. After the test plan was completed the specimens were sectioned for scanning electron microscope (SEM) analysis of the slice region and the surface.

\subsection{General Observations}

Following the mounting procedure, there appeared to be some evidence of tensile overload at the end of the slice in some specimens. Following electron and proton exposures there were no obvious changes to the specimens, although solar absorptance measurements showed a slight increase (see Table 5) [8]. Following ten-year AO exposures, the specimens had a matte finish common in AO degradation of materials; this was detected in the solar absorptance measurements [8]. No changes were noted after $\mathrm{x}$-ray exposure. Most changes were observed following thermal cycling. 


\subsubsection{Thermal Cycling}

Exposure set Bl (electron, proton, $\mathrm{x}$-ray) was cycled while spring loaded at LeRC, and most of the specimens experienced crack growth. Two specimens (B1.2, B1.4) tore in two along the pre-exposure slice before the 1000 cycles were completed, and specimen B1.8 (the current HST material) was torn most of the way across the width by the end of the cycles. Specimens B1.1 and B1.5 had yellowed regions that seemed to be associated with the adhesive.

Exposure sets M1 and M3 experienced 20,000 thermal cycles at GSFC following electron, proton and AO exposure. The specimens appeared dramatically different following thermal cycling. Before cycling, the surface had a diffuse appearance but still seemed mostly transparent; there was no evidence of yellowing. After cycling the materials were milky and the surfaces were

nearly opaque. It is believed that the thermal cycling opened micro-cracks at $\mathrm{AO}$ erosion trough sites. This appearance change was detected in the solar absorptance measurements. Some specimens also appeared yellowed at the edges; this seemed to be associated with the adhesive. In addition, most of the specimens exhibited some crack propagation.

Set M2 experienced 3,200 thermal cycles at GSFC following electron, proton and $\mathrm{x}$-ray exposure. Several specimens exhibited crack growth. M2.4 delaminated at the interface between the FEP and the VDA, and the crack propagated most of the width of the specimen.

\subsection{Solar Absorptance Measurements}

Before and after each exposure and the total exposure, the solar absorptance was measured in air. Some materials with radiation induced solar absorptance degradation will, to some extent, recover their optical properties when exposed to air. This bleaching in air has been well documented in the literature for white paints $[9,10]$. However, orbital data and short term ground testing data indicate that the solar absorptance of $\operatorname{Teflon}^{\oplus}$ FEP is relatively stable $[10,11]$. For convenience and speed, the measurements were made in air. Since most of the materials were very similar, and since the FRB was interested primarily in ranking the performance of the materials, this issue was not considered significant for this effort. However, it is possible that the solar absorptance data was skewed if bleaching occurred. 
In most cases, measurements were made with Laboratory Portable Spectroreflectometers (LPSR), and the solar absorptance was calculated in accordance with ASTM E903-82. Following the $\mathrm{x}$-ray exposure and subsequent thermal cycling at LeRC, the absorptance was measured using a UV-Vis-NIR Spectrophotometer (Perkin-Elmer, $\lambda$-9) equipped with a $150 \mathrm{~mm}$ integrating sphere. Total spectral reflectance was obtained from 250 to $2,500 \mathrm{~nm}$. The spectral data were convoluted into the air mass zero solar spectrum over the same wavelength range and integrated to obtain solar total reflectance $\left(\rho_{\mathrm{t}}\right)$. Solar absorptance $\left(\alpha_{\mathrm{s}}\right)$ was calculated by subtracting $\rho_{\mathrm{t}}$ from 1. Spectral reflectance uncertainty for the $\lambda-9$ is $\pm 2 \%$, while repeatability $\pm 0.5 \%$.

The LPSR and $\lambda-9$ use similar reference specimens (spectralon) and were set to measure across the same wavelength range (250 to $2,500 \mathrm{~nm}$ ), so some comparison can be made. However, because different instruments were used, the changes in absorptance (rather than the absolute absorptance) were considered in comparing data. The largest changes in solar absorptance occurred during thermal cycling of exposure set M1. Additional increases were noticed following UV exposure. The solar absorptance values are reported in Table 5.

Solar absorptance measurements were not taken prior to thermal cycling for sets M1, M2 and M3. The change in solar absorptance recorded in Table 5 was calculated by subtracting the change due to all the other exposures from the overall change. Final measurements were not taken for exposure set B1 before the specimens were sectioned, so the values were estimated by summing the change in solar absorptance from each exposure and the initial measurement. 
TABLE 5: CHANGE IN SOLAR ABSORPTANCE $(\Delta \alpha)$ FOLLOWING

ENVIRONMENTAL EXPOSURES

\begin{tabular}{|c|c|c|c|c|c|c|c|c|}
\hline & & \multicolumn{9}{|c|}{$\Delta \alpha$ Following Each Exposure } & \multicolumn{2}{c|}{ Post Test } \\
Sample & Initial & $\alpha$ & $\begin{array}{c}\text { Charged } \\
\text { Particles }\end{array}$ & $\begin{array}{c}\text { Atomic } \\
\text { Oxygen }\end{array}$ & $\begin{array}{c}\text { Flare } \\
\text { X-ray }\end{array}$ & $\begin{array}{c}\text { Thermal } \\
\text { Cycling }\end{array}$ & Near UV & $\begin{array}{c}\alpha \\
\Delta \alpha\end{array}$ \\
\hline M1.1 & 0.092 & -0.001 & 0.017 & & $0.292^{*}$ & 0.039 & 0.439 & 0.347 \\
M1.2 & 0.076 & 0 & 0.022 & & $0.007^{*}$ & 0.068 & 0.173 & 0.097 \\
M1.3 & 0.146 & 0.007 & 0.030 & Not & $0.158^{*}$ & 0.071 & 0.412 & 0.266 \\
M1.4 & 0.167 & 0 & 0.040 & Exposed & $0.119^{*}$ & -0.006 & 0.320 & 0.153 \\
M1.5 & 0.080 & 0.004 & 0.025 & & $0.251^{*}$ & 0.029 & 0.389 & 0.309 \\
M1.6 & 0.138 & 0 & 0.033 & & $0.083^{*}$ & 0.050 & 0.304 & 0.166 \\
M1.8 & 0.139 & 0.007 & 0.024 & & $0.067^{*}$ & -0.010 & 0.227 & 0.088 \\
\hline M2.1 & 0.093 & 0 & & 0.001 & $0.112^{*}$ & & 0.206 & 0.113 \\
M2.2 & 0.079 & -0.001 & & 0 & $0.010^{*}$ & & 0.088 & 0.009 \\
M2.3 & 0.161 & 0.004 & Not & 0.001 & $0.046^{*}$ & Not & 0.212 & 0.051 \\
M2.4 & 0.174 & 0 & Exposed & 0 & $00^{*}$ & Exposed & 0.168 & -0.006 \\
M2.5 & 0.081 & 0 & & 0 & $0.039^{*}$ & & 0.093 & 0.012 \\
M2.6 & 0.140 & 0 & & 0.001 & $0.008^{*}$ & & 0.149 & 0.009 \\
M2.8 & 0.133 & 0.002 & & 0.001 & $0.036^{*}$ & & 0.172 & 0.039 \\
\hline M3.1 & 0.139 & 0.007 & 0.040 & No Exp. & $0.061^{*}$ & .022 & 0.269 & 0.130 \\
\hline B1.1 & 0.087 & 0.004 & & 0 & 0.063 & & $0.154^{*}$ & \\
B1.2 & 0.081 & -0.002 & & -0.001 & 0.003 & & $0.081^{*}$ & \\
B1.3 & 0.152 & 0.002 & & 0 & -0.005 & & $0.149 *$ & \\
B1.4 & 0.178 & -0.003 & Not & 0 & 0.002 & Not & $0.177^{*}$ & \\
B1.5 & 0.081 & 0.002 & Exposed & 0.003 & 0.041 & Exposed & $0.127^{*}$ & \\
B1.6 & 0.135 & 0.002 & & 0 & -0.007 & & $0.130^{*}$ & \\
B1.7 & 0.336 & 0.004 & & - & -0.001 & & $0.339^{*}$ & \\
B1.8 & 0.135 & 0.003 & & -0.004 & 0.008 & & $0.142^{*}$ & \\
B1.9 & 0.076 & 0.001 & & - & Not & & & \\
B1.0 & 0.172 & 0.006 & & 0.003 & Exposed & & $0.181^{*}$ & \\
\hline & & & & & & & & \\
\end{tabular}

* Values calculated rather than measured (see section 4.2)

\subsection{Scanning Electron Microscopy (SEM)}

When all of the exposures were completed, the specimens were sectioned, and SEM analysis was performed. The end of the slice region was analyzed to detect propagation and to study the morphology of the crack. Four basic types of fractures were found: tensile overload (TO), slow crack propagation 1 (SC1), slow crack propagation 2 (SC2), and combinations of TO and slow cracking (TO1 or TO2). The features and causes of these fractures are described below, and Table 6 summarizes the type of cracking observed by material and exposure set. Crack extent (length) is addressed in Section 4.3.5 and Table 7. 


\subsubsection{Tensile Overload (TO)}

The TO crack surfaces showed plastic deformation with long fibrous tears and thin rippled layers (see Figure 4). This type of failure occurred when the load applied to the specimen, combined with stress concentration at the end of the slice, exceeded the material's ultimate strength while the material was relatively ductile.

In specimens exposed to $\mathrm{AO}$, the crack surface appeared fibrous. The fibers were oriented in the through-thickness direction and showed little plastic deformation. The AO surface damage appeared to serve as crack-initiating flaws, allowing tensile overload without plastic deformation. The cracks appeared to progress away from the initial notch; the actual crack front tended to move from the AO-exposed surface to the opposite surface.

Evidence of TO was found in specimens B1.1, B1.2, B1.3, B1.4, and B1.7 (see Table 6).

\subsubsection{Slow Crack Propagation 1 (SC1)}

The $\mathrm{SCl}$ crack surfaces were very flat and perpendicular to the specimen surface. There was very little deformation at the specimen surface. The areas between striations were relatively smooth, and there was no evidence of plastic deformation (see Figure 2). A combination of stress from thermal contraction of the constrained specimen and possible change in material properties during low temperature cycles caused the crack to propagate a short distance. The high temperature portion of the cycle allowed the crack tip to close, therefore the low temperature excursions started with a relatively sharp crack tip. The fracture surface of these cracks most closely resembled those from retrieved HST materials [4].

Evidence of SC1 was found in specimens M1.2, M1.4, M2.3, M2.4, and M2.5 (see Table 6).

\subsubsection{Slow Crack Propagation 2 (SC2)}

The SC2 crack surfaces were wavy, with some deformation at the specimen surface in the direction perpendicular to the specimen surface. Ductile tearing was observed between and at the crests of wavy striations (see Figure 3). As with the $\mathrm{SC}$, the crack front progressed during thermal cycles. The tension on the specimen was sufficient to cause some plastic deformation. 
Because the specimen was always under tension, the crack tip did not close with each high temperature excursion. Therefore, low temperature cycles started with a blunted, stressed crack tip.

Evidence of SC2 was found only in combination with TO (TO2, see Table 6).

\subsubsection{Combination (TO1 or TO2)}

The features of the crack were consistent with single tensile overload adjacent to the initial slit and then changed to either SC1 or SC2 described above. This crack occurred when the initial yielding (TO) reduced the stress concentration below that necessary for failure. The crack then progressed as SC1 or SC2 depending upon the conditions (see Figure 4).

Evidence of TO1 or TO2 was found in specimens M1.5, M2.2, M3.1, B1.5, B1.6, and B1.8 (see Table 6).

TABLE 6: CRACK FEATURES BY CANDIDATE AND SET

\begin{tabular}{|c|c|c|c|c|c|}
\hline \multirow[b]{2}{*}{ Material } & \multirow{2}{*}{$\begin{array}{c}\text { Sample } \\
. \#\end{array}$} & \multicolumn{4}{|c|}{ Crack Type } \\
\hline & & M1 Set & M2 Set & M3 Set & B1 Set \\
\hline $10 \mathrm{mil}$ FEP/VDS/Inconel/adhesive/Nomex & 1 & None & None & & TO \\
\hline $\begin{array}{l}5 \mathrm{mil} \text { FEP/VDS/Inconel/adhesive/ fiberglass } \\
\text { scrim/adhesive/Kapton }\end{array}$ & 2 & $\mathrm{SC} 1$ & $\mathrm{TO} 2$ & & TO \\
\hline 10 mil FEP/VDA/adhesive Nomex & 3 & None & $\mathrm{SCl}$ & & TO \\
\hline $\begin{array}{c}5 \text { mil FEP/VDA/adhesive/fiberglass } \\
\text { scrim/adhesive/Kapton }\end{array}$ & 4 & $\mathrm{SCl}$ & $\mathrm{SCl}$ & & TO \\
\hline 5 mil FEP/VDS/Inconel/adhesive/Nomex & 5 & TO1 & SC1 & & TOI \\
\hline 5 mil FEP/VDA/adhesive/Nomex & 6 & None & None & & $\mathrm{TO} 2$ \\
\hline OCLI/White Tedlar & 7 & - & - & & TO \\
\hline 5 mil FEP/VDA & 8 & TO & None & TO1 & TO2 \\
\hline SiO2/Al2O3/Ag/Al2O3/Stainless & 9 & - & - & & None \\
\hline AZ93 White/Kapton & 0 & - & - & & None \\
\hline
\end{tabular}

\subsubsection{Crack Extent}

SEM images of the specimens were used to determine how far the cracks propagated from the edge of the pre-exposure slit. Since many of the candidates were layered with different types of scrim, crack length alone was not an effective illustration of the material performance. Table 7 contains descriptive data about the crack propagation in each specimen and each exposure set. 
All of the specimens in the Bl exposure set experienced tensile overload. This was most likely caused by the nominal 1800 psi tensile stress during the thermal cycling. Materials in exposure set M2 most frequently experienced slow crack growth similar to the retrieved HST materials.

Specimens with fiberglass scrim (materials 2,4 ) experienced the worst cracking. In all test sets these materials showed crack propagation, often accompanied by delamination between the FEP and the VDA or VDS. In the overly-rigorous load conditions of the B1 exposure set, these materials failed completely.

In specimens with Nomex scrim (materials $1,3,5,6)$ the crack propagation past the preexposure slit stopped before the first or second scrim fiber. Often there was evidence of minor delamination between the FEP and the VDA or VDS.

TABLE 7: CRACK FEATURES BY MATERIAL AND EXPOSURE SET

\begin{tabular}{|c|c|c|c|c|c|c|}
\hline \multirow{3}{*}{$\begin{array}{c}\text { Material } \\
\text { Number }\end{array}$} & \multicolumn{3}{|c|}{ M1 Set } & \multicolumn{2}{|c|}{ M2 Set } & \multicolumn{2}{c|}{ B1 Set } \\
\cline { 2 - 7 } & Type & Extent & Type & Extent & Type & Extent \\
\hline 1 & None & - & None & - & TO & to next fiber \\
2 & SC1 & delam; long & TO2 & short, no delam & TO & tore in two \\
3 & None & - & SC1 & short of next fiber & TO & to 2nd fiber \\
4 & SC1 & long, no delam & SC1 & delam, very long & TO & tore in two \\
5 & TO1 & delam; to next fiber & SC1 & to 2nd fiber & TO1 & to next fiber, delam \\
6 & None & - & None & - & TO2 & delam, to next fiber \\
7 & - & - & - & - & TO & long micro crack \\
8 & TO & short & None & - & TO2 & mixed, 3/4 of width \\
9 & - & - & - & - & None & - \\
0 & - & - & - & - & None & - \\
\hline
\end{tabular}

\section{SELECTION}

The FRB used the candidate selection process described in section 2.1 to rank the candidate materials following the environmental exposures. The materials were evaluated based on their performance with respect to each of the nine factors. Two materials, Proprietary Teflon ${ }^{\otimes} / \mathrm{AZ} 93$ White Paint/Kapton ${ }^{\star}$ (material 0) and $\mathrm{SiO}_{2} / \mathrm{Al}_{2} \mathrm{O}_{3} / \mathrm{Ag} / \mathrm{Al}_{2} \mathrm{O}_{3} / 4$ mil stainless steel (material 9) were not 
considered in this final evaluation. Material 0 was eliminated prior to voting because of problems with particulate contamination and UV darkening.

Early on in the testing of the candidates, a programmatic decision was made by HST project management to use material 9 (composite coating on stainless steel) for repairs to the equipment bays. The equipment bays contain electronics and were designed to be serviced by astronauts during planned extra-vehicular activities. This meant that the thermal and handling issues for the new material for the equipment bays were different from those for the rest of the telescope. The size, shape and degree of detail on the equipment bay doors made the coating/stainless an ideal solution, and this coating has a twenty-five year successful flight history predating the use of second-surface mirror films (e.g. metallized Teflon ${ }^{\otimes}$ FEP). Although material 9 was ideal for the equipment bays, it was not practical for the majority of the repairs in terms of cost, handling or production. Therefore, it was not considered by the FRB in making its selection.

The remaining candidate replacement materials were ranked as in Table 8.

TABLE 8: FINAL RANKING OF CANDIDATE MATERIALS

\begin{tabular}{|c|c|c|}
\hline Rank & $\begin{array}{l}\text { Material } \\
\text { Number }\end{array}$ & Material \\
\hline 1 & 6 & 5 mil Teflon ${ }^{3 E P} /$ DDA/adhesive Nomex ${ }^{3}$ scrim \\
\hline 2 & 3 & 10 mil Teflon ${ }^{\star}$ FEP/VDAadhesive/Nomex ${ }^{\star}$ scrim \\
\hline 3 & 8 & 5 mil Teflon ${ }^{\infty}$ FEP/VDA (the current material) \\
\hline 4 & 1 & 10 mil Teflon ${ }^{\otimes}$ FEP/VDS/Inconel/adhesive/Nomex ${ }^{\otimes}$ scrim \\
\hline 5 & 5 & 5 mil Teflon ${ }^{\otimes}$ FEP/VDS/Inconel/adhesive/Nomex ${ }^{\star}$ scrim \\
\hline 6 & 2 & 5 mil Teflon ${ }^{\otimes}$ FEP/VDS/Inconel/adhesive/fiberglass scrim/adhesive/2 mil Kapton ${ }^{\otimes}$ \\
\hline 7 & 7 & OCLI multi-layer oxide UV blocker 2 mil white Tedlar $^{\oplus}$ \\
\hline 8 & 4 & 5 mil Teflon ${ }^{\otimes}$ FEP/VDA/adhesive/fiberglass scrim/adhesive/2 mil Kapton ${ }^{\star}$ \\
\hline
\end{tabular}

Material 6, (5 mil Teflon ${ }^{\otimes}$ FEP /VDA/non-UV-darkening adhesive/Nomex scrim), was ranked first and recommended as the replacement material for the new outer layer. However, there was some concern that the absorptance value would increase significantly with more UV exposure. Specimen M2.6 was placed back in the UV chamber at GSFC for additional exposure and 
absorptance measurements. In the event that the recommended material failed this final test, two alternates that had not been included in this test plan were suggested.

The first alternate was $\mathrm{SiO}_{2} / \mathrm{Al}_{2} \mathrm{O}_{3} / \mathrm{Ag} / \mathrm{Al}_{2} \mathrm{O}_{3} / \mathrm{Kapton}{ }^{\star}$. This material had excellent thermal properties, and the coating proved durable in the electron and proton exposures and the large specimen thermal cycling. The second alternate was unsupported 10 mil Teflon ${ }^{\circledast E P}$. This material had the advantages of being commercially available and relatively inexpensive. Also, the 10 mil candidates seemed to perform better in crack resistance than the 5 mil candidates. The project management for HST will make the final selection based on program requirements.

\section{CONCLUSION}

Based on the nine performance criteria established by the FRB at the beginning of the exposures, material 6 (5 mil Teflon ${ }^{\circledast E P / V D A / n o n-U V-d a r k e n i n g ~ a d h e s i v e / N o m e x ~}{ }^{\circledast}$ scrim) was recommended as the new outer layer for the MLI on the HST Light Shield. The two most important factors in this selection were the optical properties and the mechanical integrity following the simulated space exposures. Although the absorptance of the selected material did not meet the end-of-life requirements, it was the best performer among the specimens that maintained mechanical integrity. Since limited UV exposure was possible during the test plan, UV exposure continues so that the maximum absorptance of this material can be determined before the final decision is made.

Fracture surfaces that resembled those of retrieved HST specimens were observed on several specimens in the M2 exposure set and on two specimens in the M1 exposure set. The highest increase in solar absorptance occurred in exposure set M2. Material 1 (10 mil Teflon FEP/VDS/Inconel/adhesive/Nomex ${ }^{\otimes}$ scrim) had the highest increase in solar absorptance in each exposure set. 


\section{ACKNOWLEDGMENTS}

The staff at the environmental exposure facilities were Dave Edwards (MSFC), Jason Vaughn (MSFC), Dennis Russell (Boeing), Larry Fogdall (Boeing), Wanda Peters (Swales Aerospace), Edward Sechkar (NYMA, Incorp.), and David Scheiman (NYMA, Incorp.). Sample preparation was done by Mary Ayres-Treusdell (GSFC), Tom Zuby (Unisys), and Dave Hughes (Swales Aerospace). Fluence calculations for HST were performed by Teri Gregory (Lockheed Martin Technical Operations), Janet Barth (GSFC), and Shaun Thomson (GSFC). 


\section{REFERENCES}

1. Zuby T, de Groh K, and Smith D 1995 "Degradation of FEP Thermal Control Materials Returned from the Hubble Space Telescope", NASA Technical Memorandum 104627.

2. Hansen PA, Townsend JA, Yoshikawa Y, Castro JD, Triolo JJ, and Peters WC 1998 "Degradation of Hubble Space Telescope Metallized Teflon ${ }^{\boxplus}$ FEP Thermal Control Materials", Science of Advanced Materials and Process Engineering Series, $\underline{43}$, p. 570-81.

3. Townsend JA, Hansen PA, Dever JA, Triolo JJ 1998 "Analysis of Retrieved Hubble Space Telescope Thermal Control Materials", Science of Advanced Materials and Process Engineering Series, 43 , p. 582-93.

4. Wang L, Townsend JA, and Viens M 1998 "Fractography of MLI Teflon ${ }^{\circledR}$ FEP from the HST Second Servicing Mission", Science of Advanced Materials and Process Engineering Series, $\underline{43}$, p. $594-606$.

5. Dever J 1997 "Summary of HST MLI Materials Analysis Results", NASA Internal Memorandum.

6. He C and Townsend JA 1998 "Solar Absorptance of the Teflon ${ }^{\circledR}$ FEP Samples Returned from the HST Servicing Missions", Science of Advanced Materials and Process Engineering Series, $\underline{43}$, p. 607-15.

7. Banks B, Stueber T, Rutledge S, Jaworske D, and Peters W 1998 "Thermal Cycling-Caused Degradation of Hubble Space Telescope Aluminized FEP Thermal Insulation”, AIAA 980896. 
8. Townsend JA, Hansen PA, McClendon MW, Dever JA, and Triolo J 1998 "Evaluation and Selection of Replacement Thermal Control Materials for the Hubble Space Telescope", Science of Advanced Materials and Process Engineering Series, 43, p. 968-82.

9. Dever JA, Rutledge SK, Bruckner EJ, Stidham CR, Stueber TJ, Booth RE, "The Effects of Simulated Low Earth Orbit Environments on Spacecraft Thermal Control Coatings," Science of Advanced Materials and Process Engineering Series, 38, pp. $694-706$ (1993).

10. Wilkes DR, LeMaster PS, Mell RJ, Miller ER, "Trend Analysis of In Situ Spectral Reflectance Data from the Thermal Control Surfaces Experiments (TCSE)", LDEF-96 Months in Space Third Post-Retrieval Symposium, NASA CP 3275, Part II, 755-769, 1993.

11. Dever JA, Rutledge SK, Hasegawa MM, Reed CK, "Evaluation of Low Earth Orbit Environmental Effects on International Space Station Thermal Control Materials," NASA TM-1998-208500, August 1998. 


\section{ILLUSTRATIONS}

Figure 1. Fractional Distortion, $\mathrm{d} / \mathrm{h}$

Figure 2. Slow Crack Propagation in Specimen M2.5

Figure 3. Tensile Overload in Specimen B1.8

Figure 4. Combined Tensile Overload and Slow Crack Propagation in Specimen B1.6 

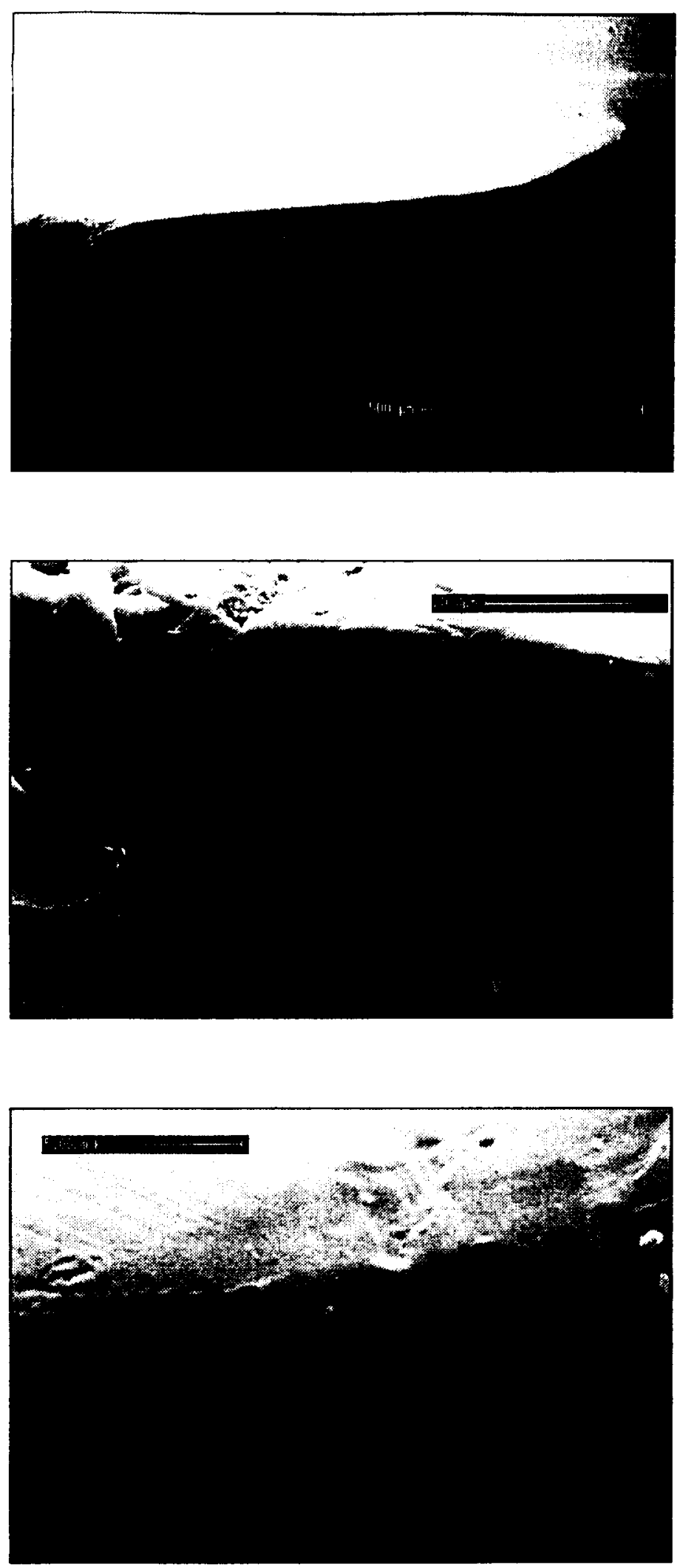

Figure 2. Slow Crack Propagation in Specimen M2.5
Figure 2c. Specimen M2.5, Detail of striations on the crack surface and the exposed FEP.
Figure 2a. Specimen M2.5, Entire crack length including initial razor cut at the far left. Nomex ${ }^{\star}$ fibers are revealed behind the crack opening in the center. Silver/Inconel layer is visible at the crack tip to the right.

Figure 2b. Specimen M2.5, Initial crack surface, relatively smooth with fine striations. 

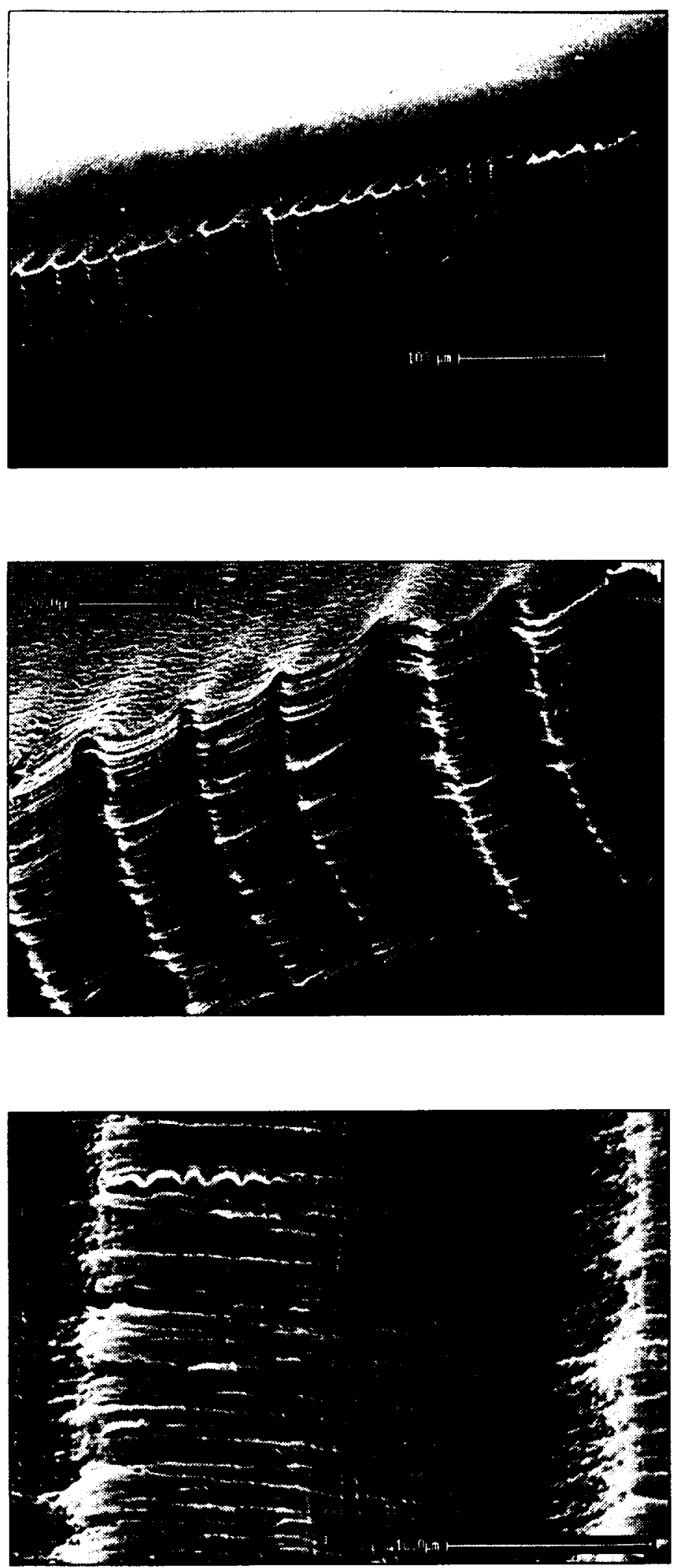

Figure 3a. Specimen B1.8, Five mil FEP with VDA, Spring loaded during thermal cycling. Shows wave-like striations. Crack propagation was right to left.

Figure 3b. Detail of the crack surface of specimen B1.8. Crack propagation was right to left.
Figure 3c. Detail of wave-like striations showing ductile tearing features, specimen B1.8. 

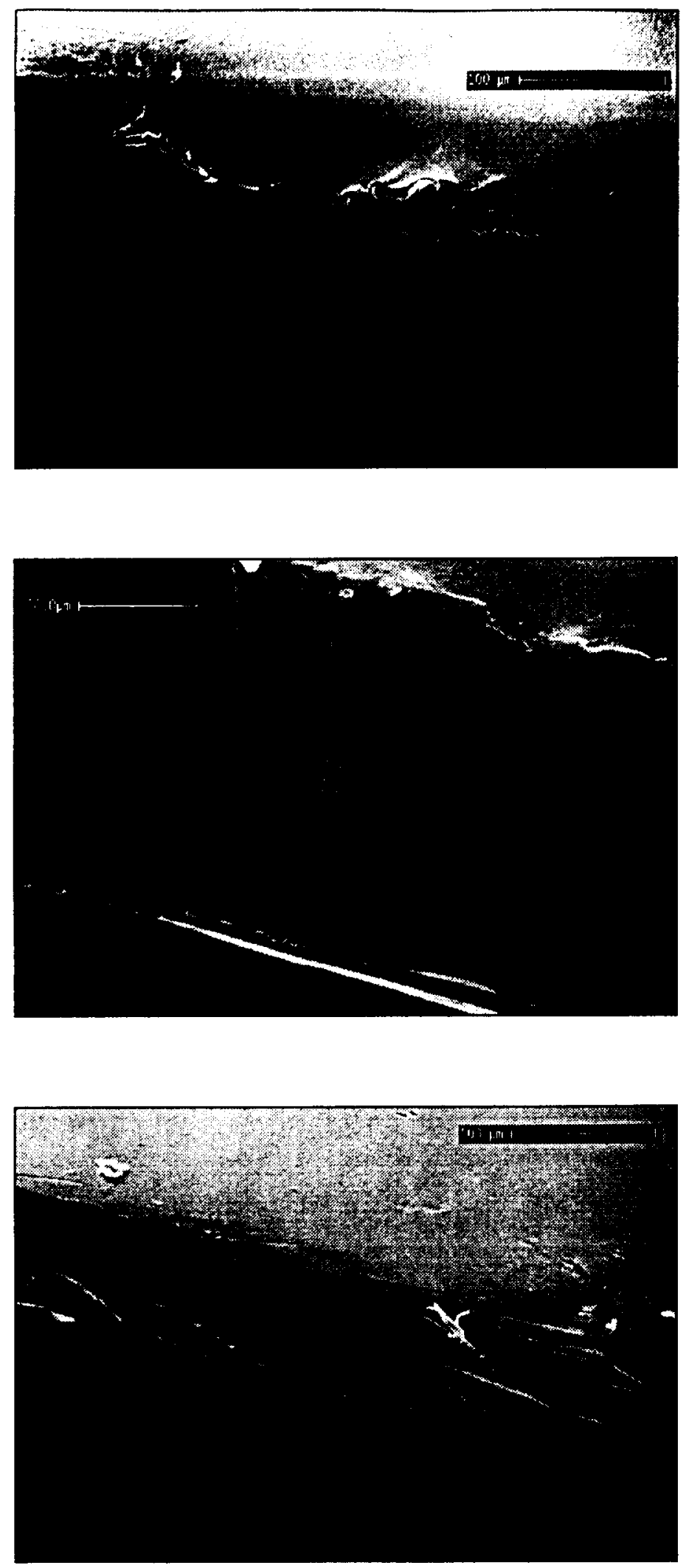

Figure 4a. Specimen B1.6. The initial razor cut is visible at the far left. The crack surface shows significant plastic deformation. Beginning of progressive crack formation is apparent at the far right. Crack propagation was left to right.

Figure 4b. Specimen B1.6. Midpoint of crack length. Crack propagation was left to right.

Figure 4c. Specimen B 1.6. End of crack. Secondary cracks associated with main crack striations are apparent. Plastic deformation at the extreme right was created during SEM specimen preparation. 